IZA DP No. 10018

Does Social Health Insurance Reduce Financial Burden?

Panel Data Evidence from India

Mehtabul Azam

June 2016 


\title{
Does Social Health Insurance Reduce Financial Burden? Panel Data Evidence from India
}

\author{
Mehtabul Azam \\ Oklahoma State University \\ and IZA
}
Discussion Paper No. 10018 June 2016

IZA
P.O. Box 7240
53072 Bonn
Germany

Phone: +49-228-3894-0

Fax: +49-228-3894-180

E-mail: iza@iza.org

\begin{abstract}
Any opinions expressed here are those of the author(s) and not those of IZA. Research published in this series may include views on policy, but the institute itself takes no institutional policy positions. The IZA research network is committed to the IZA Guiding Principles of Research Integrity.

The Institute for the Study of Labor (IZA) in Bonn is a local and virtual international research center and a place of communication between science, politics and business. IZA is an independent nonprofit organization supported by Deutsche Post Foundation. The center is associated with the University of Bonn and offers a stimulating research environment through its international network, workshops and conferences, data service, project support, research visits and doctoral program. IZA engages in (i) original and internationally competitive research in all fields of labor economics, (ii) development of policy concepts, and (iii) dissemination of research results and concepts to the interested public.
\end{abstract}

IZA Discussion Papers often represent preliminary work and are circulated to encourage discussion. Citation of such a paper should account for its provisional character. A revised version may be available directly from the author. 
IZA Discussion Paper No. 10018

June 2016

\section{ABSTRACT}

\section{Does Social Health Insurance Reduce Financial Burden? Panel Data Evidence from India}

Indian government launched the Rashtriya Swasthya Bima Yojana (RSBY), a national health insurance scheme, in 2008 that provides cashless health services to poor households in India. We evaluate the impact of RSBY on RSBY beneficiary households' (average treatment impact on the treated) utilization of health services, per capita out-of-pocket (OOP) expenditure, and per patient OOP expenditures on major morbidities. To address the issue of non-randomness in enrollment into the scheme, we exploit the longitudinal aspect of a large nationally representative household survey data to implement a difference-in-difference with matching. We find some evidence of positive impact of RSBY on utilization of health services by RSBY beneficiary households in rural India but not in urban India. However, there is no evidence that the RSBY reduced per person OOP expenditure for RSBY households in both rural and urban areas. Conditional on having received medical treatment for major morbidity, we find that RSBY increased probability of hospitalization and being treated by a government doctor in rural areas but no significant impact in urban areas. We also find lower expenditure on medicine for a RSBY cardholder patient in rural areas.

JEL Classification: I1, I18, I38

Keywords: $\quad$ SHI, RSBY, IHDS, out-of-pocket expenditure, health services utilization

Corresponding author:

Mehtabul Azam

326 Business Building

Spears School of Business

Oklahoma State University

Stillwater, OK 74078

USA

E-mail:mazam@okstate.edu 


\section{Introduction}

Access to health services, education, food, water, housing, sanitation, and information as well as enjoyment of a basic level of income security are, human rights enshrined in the Universal Declaration of Human Rights. Social protection is an important factor in enabling people to exercise these rights (UNDP, 2011). In recent past, Indian Parliament has passed many legislations towards achievement of these rights, such as National Rural Employment Guarantee Act that guarantees 100 days of work at minimum wage per family in a year, Right to Education Act that provides free and compulsory education for children between 6 and 14 till completion of elementary education in a neighborhood school. In the same spirit, Government of India (GOI) introduced a National Health Insurance Scheme known as Rashtriya Swasthya Bima Yojana (RSBY) in early 2008 that was initially designed to target only the Below Poverty Line (BPL) households, but has been expanded to cover other defined categories of unorganized workers.

Health care in India is financed through various sources, including individual out-ofpocket (OOP) payments, central and State government tax revenues, external aid and profits of private companies. National Health Accounts data from 2004-2005 show that central, State and local governments together account for only about 20 per cent of India's total health expenditure. More than 78 per cent of the health expenditure comprised OOP expenditures - one of the highest rates in the world. External aid to the health sector accounted for a negligible 2 per cent of the total health expenditure (Swarup and Jain, 2011). Given the large share of OOP payments in health care in India, RSBY is considered a very innovative scheme that relies on providing cashless health services to the beneficiary households without any paperwork with the use of smart cards (more details are provided in section 1.1) with only a marginal enrollment/renewal cost of 30 Indian Rupees (INR) (about $\$ 0.5)$ per year. ${ }^{1}$ It covers up to five members of family. As of November, 2012, 33.19 million

\footnotetext{
${ }^{1}$ The World Bank hailed RSBY as a model of good design and implementation with important lessons for other programs in India. http://pib.nic.in/newsite/efeatures.aspx?relid=69262
} 
BPL families were enrolled in RSBY, and an estimated 165.9 million persons were a part of "BPL-families-with-a-RSBY-card" (Ministry of Labour and Employment, 2012).

In this paper, we evaluate the impact of RSBY on RSBY beneficiary households' (Average Treatment Impact on the Treated, ATT) utilization of health services, per capita in-patient, out-patient, and total OOP expenditure. We distinguish betweeen utilisation of health services for short term morbidity and long term morbidity, and also consider different components of health expenditure such as hospitalization cost, medicine cost, and transportation cost. In addition, we also provide impact of RSBY on an individual's utilization of health services and expenditure conditional on having recieved medical treatment (i.e. actual patient). Using a nationally representative longitudinal survey, we combine difference-in-difference with matching to mitigate the self-selection issue that induces biases in impact evaluation of health insurances. Difference-in-difference with matching should take care of selection issues as long as the macro trend observed between treated and non-treated households remain same. Since we use the non-treated households from same area, and our propensity score matching does a good job in balancing the characteristics in baseline across RSBY and non-RSBY households, the assumption is likely to be satisfied.

The Indian experiment with social health insurance is not new, and several developing countries have recently used tax revenues to subsidize health insurance for informal-sector (usually rural) workers and their families, or at least the poorer ones among them (Wagstaff et al., 2009). For example, Indonesia launched a health insurance scheme for the poor in 2004 with the ultimate objective of bringing all Indonesians (including those who are currently enrolled in social insurance schemes for formal sector workers) under one cover (Rokx et al., 2009). In 2003, China adopted a new health insurance system, the New Cooperative Medical Scheme (NCMS), in rural areas where $80 \%$ of people were without health insurance of any kind (Wagstaff et al., 2009). The WHO (2010) and the World Bank (Hsiao and Shaw 2007) have endorsed the restriction of OOP expenditures for health care at the time of use through the prepayment of insurance as an important step toward averting the financial hardship 
associated with paying for health care (Acharya et al., 2012). Acharya et al. (2012) present a systematic review of the literature on the extent to which social health insurance schemes enhance access to care and offer protection from financial risk to households in the informal sector. $^{2}$

There is a growing interest and literature on RSBY. A number of studies examine the enrollment into RSBY. Nandi et al. (2013) use district-wise official data on RSBY enrollment, and correlate those with district characteristics. Based on OLS and probit, they find that political and institutional factors are among the strongest determinants explaining the variation in participation and enrollment in RSBY. Districts with a higher share of socioeconomically backward castes are less likely to participate, and their enrollment rates are also lower. Das and Leino (2011) find that Information and Education Campaign in Delhi is not associated with higher enrollment. Another set of studies examine the RSBY households from certain geographical locations. Rathi et al. (2012) and Devadasan et al. (2013) use data from families enrolled in RSBY from one district (Amaravati district in the state of Maharashtra and Patan district in the state of Gujarat, respectively), and find that a large proportion of families enrolled in RSBY continue to incur OOP spending despite that RSBY is a cashless scheme with no co-payment or fees at point of service.

Unlike the above-mentioned studies which are based on beneficiary surveys in few districts, Johnson and Krishnaswamy (2012) use cross-section consumption surveys conducted by National Sample Survey (NSS) in 2004-05 and 2009-10. They matched districts based on the characteristics, and use a difference-in-difference strategy across RSBY districts vs non-RSBY districts. They find a small decrease in out-of-pocket household outpatient expenditure, and limited evidence of increase in the number of households that have had a hospitalization case. Similar to Johnson and Krishnaswamy (2012), Karan et al. (2015) use NSS cross-section consumption expenditure data from 1999-00, 2004-05, and 2011-12, and study the impact of RSBY on per household member monthly OOP spending, and share

\footnotetext{
${ }^{2}$ Ekman (2004) provides a review of the literature on community based health insurance (CBHI) schemes.
} 
of the OOP expenditure in households' monthly budget. Their identification strategy also relies on treating all households residing in RSBY districts as treated and all households residing in non-RSBY districts as non-treated. They do not find significant impact of RSBY on OOP expenditure. In essence, both Johnson and Krishnaswamy (2012) and Karan et al. (2016) provide estimates for 'intention to treat' (ITT) effect, and not the average treatment effect on the treated (ATT). Although ITT is a useful policy parameter, in the case of low uptake of the program it has limited usefulness. In addition, given that medical insurances are targeted towards specific households, the impact on beneficiary households is warranted.

Raza et al. (2016) use a panel household survey collected from rural areas of three districts (two from the state of Uttar Pradesh and one from the state of Bihar) in India. They examine the determinants of enrollment and drop-out from RSBY. Using household fixed effects, they found RSBY membership is not significantly associated with the likelihood of hospitalization. However, they find that RSBY membership to be associated with a reduction in OOP spending in Bihar but not in Uttar Pradesh.

We add to the literature in following way. First, we add to the growing literature on social health insurance (SHI) by evaluating a large SHI from a densely populated large country with a large share of OOP expenditures in health care. Second, unlike Johnson and Krishnaswamy (2012) and Karan et al. (2015), our estimates are ATT and not ITT. Unlike Raza et al. (2016) whose data is limited to three districts, our data is nationally representative, and our main estimates are based on difference in difference with matching. Third, in addition to the household level observations, we also use individual specific utilization of health services. We are able to distinguish expenditure on short term morbidity vs long term morbidity as the financial implications of long term morbidities are more serious than short term morbidities. Moreover, we break the total OOP expenditure in different component, such as expenditure on hospital and doctor, medicines, and transportation. Fourth, we provide impact of RSBY on individual's utilization of hospital, government doctor, and total OOP expenditures conditional on actually having received medical treatment. 
The findings of the paper is following. The RSBY households in rural India are 2.8 parentage points more likely to report a household member being treated mostly driven by higher treatment for long term morbidities (4.8 percentage points higher). There is no statistically significant impact of RSBY on hospitalization rate of RSBY households. Importantly, although there is some evidence of reduced per person household OOP expenditure in rural India, those differences are not statistically significant. RSBY households in rural India spend lower on medicines. In urban India, we do not find any significant impact of RSBY on RSBY households' utilization of health service and expenditure on health. Conditional on having received medical treatment for a long term morbidity, an individual belonging to RSBY household in rural India is 4.6 percentage points more likely to get hospitalized, 4.2 percentage points more likely to seek advice from a government doctor, and spend considerably less on medicines. However, there is no significant impact of RSBYconditional upon a person having received medical treatment for long term morbidity in urban areas.

No significant impact of RSBY on the household OOP expenditures is worrisome given the objectives of the RSBY to provide cashless health services. Nevertheless, it should also be noted that the RSBY only started in 2008 and many districts received the program in staggered way. Our 2011-12 data covers only the 1-4 years of the program's implementation, and hence runs the risk that the impacts may not yet have fully materialized as it takes considerable time to raise awareness among the poor households about their rights. As the RSBY beneficiaries get more aware about the potential services of the RSBY, it is possible that the impact of the RSBY is reflected more in the evaluation studies.

The paper is organized as follows. Section 1.1 describes the RSBY program in detail. Section 2 describes the data. Section 3 details the empirical strategy, and Section 4 presents the results. Section 5 concludes. 


\subsection{Rashtriya Swasthya Bima Yojana $(\mathrm{RSBY})^{3}$}

The Unorganized Workers Social Security Act (2008) enacted by the Central Government recommended that the Central Government provide social security schemes to mitigate risks due to disability, health shocks, maternity and old age which all unorganized workers get exposed to and are likely to suffer from. Rashtriya Swasthya Bima Yojana (RSBY) or National Health Insurance Scheme was launched in early 2008 and was initially designed to target only the Below Poverty Line (BPL) households, but has been expanded to cover other defined categories of unorganized workers. Unorganized sector workers belonging to BPL category and their family members (a family unit of five) are the beneficiaries under the scheme.

There is no premium charged to the beneficiary household. The beneficiary household only pays Indian Rupees (INR) 30 (approximately, \$0.5) per annum as registration/renewal fee. The beneficiaries are issued smart cards for the purpose of identification. The premium cost for enrolled beneficiaries under the scheme is shared by Government of India and the State governments in 75:25 ratio. State governments through a competitive public bidding process select a public or private insurance company. The financial bid is essentially an annual premium per enrolled household. The insurer must agree to cover the benefit package prescribed by Government of India through a cashless facility that in turn requires the use of smart cards which conform to certain specifications and must be issued to all members. Each contract is specified on the basis of an individual district in a state and the insurer agrees to set up an office in each district. While more than one insurer can operate in a particular state, only one insurer can operate in a single district at any given point in time.

The beneficiaries under RSBY are entitled to hospitalization coverage up to INR 30,000/per annum on family basis, for most of the diseases that require hospitalization. ${ }^{45}$ All

\footnotetext{
${ }^{3}$ The information provided in this section is taken from RSBY websites (Retrieved April 30, 2016): http://www.rsby.gov.in/about_rsby.aspx; https://india.gov.in/spotlight/rashtriya-swasthya-bima-yojana

${ }^{4} 1 \mathrm{USD}=56$ INR in June, 2012.

${ }^{5} \mathrm{RSBY}$ also includes many day care surgeries/procedures which do not require stay at hospital. A list of day care surgeries covered under RSBY are: hemodialysis, parenteral chemotherapy, radiotherapy, eye
} 
expenses related to the delivery of the baby in the hospital are also covered. Pre-existing conditions are covered from day one and there is no age limit. The coverage extends to maximum five members of the family which includes the head of household, spouse and up to three dependents. Additionally, transport expenses of INR 100/- per hospitalization will also be paid to the beneficiary subject to a maximum of INR 1000/- per year per family.

The unique feature of the scheme is use of smart cards and cashless attendance to all covered ailments. A list of the hospitals (empanelled hospitals, both public and private) is provided at the time of enrollment, and the beneficiary can choose the hospital where they want to go. The patient will not have to spend any amount for taking the treatment and hospitalization for the treatment cost up to INR 30000. It is the job of hospital to claim from the insurer. Moreover, on receipt of the smart card, the beneficiary shall be able to use health service facilities in any of the RSBY empanelled hospital across India. Any hospital which is empanelled under RSBY by any insurance company will provide cashless treatment to the beneficiary.

As of November, 2012, 33.19 million BPL families were enrolled in RSBY, and an estimated 165.9 million persons were a part of "BPL-families-with-a-RSBY-card". The scheme was implemented in 439 districts across 26 States and Union Territories. As of 31st October, 2012, a total of 12531 hospitals were empanelled under the RSBY scheme out of which 8539 (68\%) were private hospitals and $3992(32 \%)$ were public hospitals (Ministry of Labour and Employment, 2012). The program has the target to cover 70 million households by the end of the Twelfth Five Year Plan (2012-17), and could become a strong pillar for the universal health care system laid down by Government of India. $\iota$

surgery, lithotripsy (kidney stone removal), tonsillectomy, D\&C, dental surgery following an accident, surgery of hydrocele, prostrate, few gastrointestinal Surgery, genital surgery, surgery of nose, throat, ear, and urinary system, treatment of fractures/dislocation (excluding hair line fracture), contracture releases and minor reconstructive procedures of limbs which otherwise require hospitalization, laparoscopic therapeutic surgeries that can be done in day care, identified surgeries under general anesthesia, and any disease/procedure mutually agreed upon. 


\section{Data}

We use two waves of India Human Development Survey (IHDS) collected in 2011-12 and 200405 (henceforth, 2012 and 2005, respectively). The IHDS are multi-topic surveys collected jointly by University of Maryland and National Council of Applied Economic Research in New Delhi, India (See Desai et al. 2010; Desai and Vanneman, 2015 for details). Both waves are publicly available through the Inter-university Consortium for Political and Social Research (ICPSR). IHDS-2 (2012) surveyed 42,152 households in 1,503 villages and 971 urban neighborhoods across India. These data are mostly re-interviews of households interviewed for IHDS-I in 2005.

The IHDS-2 contain information on households from 375 districts, and are representative at national, state, and district level. We dropped state of Andhra Pradesh, Karnataka, and Tamil Nadu from our samples. While Andhra Pradesh and Tamil Nadu did not implemet RSBY by May 2012, all three states have more generous state-funded health insurance schemes already in operation. ${ }^{6}$ After dropping the three states, we are left with 34,102 households from 309 districts. We further drop 1484 households from our sample, as those households were not surveyed in 2005. Thus our final sample include 32,618 households from 309 districts in India. There are 48 districts in the data which were not exposed to RSBY as RSBY was not implemented in those districts by 2011-12. We treat those districts as nonexposed and drop from our main analysis which focused on comparing RSBY households with non-RSBY households in RSBY districts.

Health spending is captured in the survey both through the household expenditure module, and individual health modules. Household consumption module collected total household expenditure for in-patient (in last 365 days) and out-patient services (in last 30 days). The in-patient expenditure is divided by 12 to get monthly expenditure. In addition, the total in-patient and out-patient expenditures are divided by household size and adjusted for

\footnotetext{
${ }^{6}$ Karan et al. (2015) also drop these states from their sample. At the state level, by 2012, Andhra Pradesh had Rajiv Aarogyashri scheme, Karnataka had Yeshasvini and Vajpayee Arogyashri scheme, while Tamil Nadu had implemented Kalaignar scheme (Forgia and Nagpal, 2012).
} 
prices using rural/urban state-specific poverty lines. The per capita OOP expenditure for the household is derived by adding per capita in-patient and out-patient expenditure. In addition, we also construct share of per capita OOP in household budget by dividing the per capita OOP by per capita monthly household expenditure. We also create an indicator for household incurring catastrophic health expenditure if household total health expenditure is more than $20 \%$ of the household pre-health payment consumption expenditure. ${ }^{7}$

Individual health modules make an inquiry about each household member's health through questions about issues related to short-term morbidity such as coughs, fevers, and diarrhea, and long-term morbidity from chronic diseases ranging from asthma to cancer category. ${ }^{8}$ The health modules also collect detailed information about the medical treatment received for each individual conditional on short term (past 30 days) and long term morbidity (past 365 days) such as where the treatment was received, how many days were spent in hospital if any, days lost due to sickness, amount spent on doctors and hospital fees, medicines, and transportation. Majority of hospitalization cases are reported for long term morbidity. We create alternative utilization and expenditure from individual health modules for each individual. To establish comparability in health expenditure for short term and long term morbidity, expenditure on long term morbidity reported in survey is divided by 12 to get a monthly estimate.

Table 1 reports descriptive statistics for the outcomes variables defined at the household level for RSBY and non-RSBY households in RSBY exposed districts for baseline 2005 and 2012 data. RSBY households in rural areas are more likely to report long term illness, hospitalization, loan to meet medical expenses both in 2005 and 2012. Some of these differences may be a reflection of poor economic status of RSBY households as they are more likely to be below poverty line households. Importantly, the differences in OOP expenditures are not statistically significant. In urban India also, RSBY households are more likely to report

\footnotetext{
${ }^{7}$ The choice of $20 \%$ is arbitrary. In literature, the catastrophic health expenditure is defined using various thresholds and denominators.

${ }^{8}$ IHDS inquire whether an individual suffer frm cataract, tuberculosis, high blood pressure, heart disease , leprosy, cancer, asthma, polio, paralysis, epilepsy, STD/AIDS, accident, or other long term disease.
} 
illness, however, there is no significant difference in OOP expenditures.

Table 2 presents the descriptive statistics at the individual level conditional on a person reporting medical treatment for any long-term morbidity. We focus on long term morbidity as those expenses are more likely to be covered by RSBY rather than expenses on short term morbidity. The short term morbidities are generally not covered by RSBY unless it lead to hospitalization. The hospitalization rate for short-term morbidities is very low in our data. In rural India, conditional on getting treated for long term morbidity, there is no significant difference in hospitalization rate. However, rural households spend considerably less on medicines, hospital, and total OOP. ${ }^{9}$ In contrast, there is no statistically significant difference in medical expenses in urban areas. A patient in urban area with RSBY coverage is more likely to be hospitalized and receive treatment from a government doctor in 2012 . Importantly, this is also true in baseline period for urban areas.

Table 3 reports the descriptive statistics of variables in 2005 that might plausibly be correlated with RSBY status. In general, RSBY household's income and consumption is lower in both in urban and rural areas. Similarly, a higher proportion of RSBY households have BPL cards, more RSBY household heads' work in casual work. In rural areas (but not in urban areas), there is some evidence of adverse selection into RSBY. A higher proportion of RSBY households' member reported short-term and long-term morbidities in 2005. Some of these in morbidities might be a reflection of differences in economic status.

\section{Empirical Framework}

We use the longitudinal data to implement a matching difference-in-difference (MDID). In the presence of longitudinal or repeated cross-section data, matching and DID can be combined to weaken the underlying assumptions of both methods (Blundell and Dais, 2009). We start with a simple model that assume the outcome for household $i$ in time period $t, y_{i t}$, depends

\footnotetext{
${ }^{9}$ The IHDS data report the hospitalization and doctor cost together, and we consider the entire reported cost as hospitalization cost if a person is reported hospitalization.
} 
on household observables and unobservables in period $t$, and whether the household holds a RSBY health insurance.

$$
y_{i t}=f\left(x_{i t}\right)+\beta . r s b y_{i 1}+\gamma_{i}+\delta_{t}+\varepsilon_{i t} \text { where }=0,1
$$

where $\gamma_{i}$ is the household specific time invariant unobservables, $\delta_{t}$ represents a time specific component, and $\varepsilon_{i t}$ is household specific idiosyncratic shock. In period 0 (2005 in our context), none of the households had RSBY. In period 1 (2012 in our context), some households are covered while others are not. In other words, the treatment variable $r s b y_{i 1}$ equals 0 in period 0 , and it switches from 0 to 1 with positive probability in period 1 . $\beta$ captures the impact of RSBY.

More formally equation (1) can be written for each time period:

$$
\begin{gathered}
y_{i 1}=f\left(x_{i 1}\right)+\beta . r s b y_{i 1}+\gamma_{i}+\delta_{1}+\varepsilon_{i 1} \\
y_{i 0}=f\left(x_{i 0}\right)+\gamma_{i}+\delta_{0}+\varepsilon_{i 0}
\end{gathered}
$$

Differencing the equations (2) from (3) get rids of household time invariant unobservables $\left(\delta_{i}\right)$, and we are left with the following:

$$
\begin{gathered}
y_{i 1}^{T}-y_{i 0}^{T}=f\left(x_{i 1}^{T}-x_{i 0}^{T}\right)+\beta+\left(\delta_{1}^{T}-\delta_{0}^{T}\right)+\left(\varepsilon_{1}^{T}-\varepsilon_{0}^{T}\right) \\
y_{i 1}^{C}-y_{i 0}^{C}=f\left(x_{i 1}^{C}-x_{i 0}^{C}\right)+\left(\delta_{1}^{C}-\delta_{0}^{C}\right)+\left(\varepsilon_{1}^{C}-\varepsilon_{0}^{C}\right)
\end{gathered}
$$

where $T$ and $C$ refer Treatment (RSBY households) and Control (non-RSBY households). The expectation of the difference between the changes among the participants and the nonparticipants is equal to:

$$
E\left(\Delta y_{i}^{T}\right)-E\left(\Delta y_{i}^{C}\right)=E\left(f\left(\Delta x_{i}^{T}\right)\right)-E\left(f\left(\Delta x_{i}^{C}\right)\right)+\beta+\left(\Delta \delta^{T}-\Delta \delta^{C}\right)+E\left(\Delta \varepsilon_{i}^{T}\right)-E\left(\Delta \varepsilon_{i}^{C}\right)
$$


By careful selection of a subsample of 'treated' households (i.e. RSBY households) and 'untreated' households (i.e. non-RSBY households), and through matching each treated household with one or more untreated households who are similar in terms of observable variables, the differences in changes in outcomes due to differences in observables can be eliminated (Wagstaff et al., 2009). However, to recover impact of RSBY, we also need (a) that the period-specific aggregate shock exhibit the same trend between the treated and untreated (i.e. $\Delta \delta^{T}=\Delta \delta^{C}$ ), and (b) the expectation of the change in the idiosyncratic errors is zero among both the treated and untreated.

As argued by Wagstaff et al. (2009), there is potentially two control group. One nonparticipants residing in RSBY districts, and another all households residing in districts where RSBY was not implemented by 2012. We construct our control group from the household residing in same RSBY exposed districts (i.e. we drop the districts that were not exposed to RSBY). One can argue that aggregate shock will grow more similarly among people living in the same geographic areas than among people living in different areas - an important consideration when evaluating a program like RSBY that is also specific to certain districts.

In essence, we compare average changes in outcomes before and after the introduction of RSBY between treated and untreated households, using matching to control for (initial) heterogeneity in terms of observable variables. A simple comparison between 'treated' and 'untreated' households after the program's implementation (i.e. a single difference) would give a biased estimate of the program's impact if factors influencing enrollment in the program or placement of the program were also correlated with post-treatment outcomes. For the longitudinal data, the MDID estimator is given by following equation (Blundell and Dias, 2009):

$$
\hat{\alpha}^{M D I M, L}=\sum_{i \in T}\left\{\left[y_{i 1}-y_{i 0}\right]-\sum_{j \in C} \widetilde{w}_{i j}\left[y_{j 1}-y_{j 0}\right]\right\} w_{i}
$$

where $T$ and $C$ represent the treatment and comparison groups respectively, $\widetilde{w}_{i j}$ is the weight placed on comparison observation $j$ for the treated individual $i$ and $w_{i}$ accounts for 
the reweighting that reconstructs the outcome distribution for the treated sample (Blundell and Dias, 2009).

\subsection{Patient-level analysis}

Another interesting question is to assess the impact of RSBY on those individuals who actually received some medical treatment. For this, we restrict our sample in both 2012 and 2005 to only those individuals who reported being treated for any long term disease in last 12 months, and treat both data sets as repeated cross section. ${ }^{10}$ In this case, the matching-DID would be (Blundell and Dias, 2009):

$$
\hat{\alpha}^{M D I M, R C S}=\sum_{i \in T_{1}}\left\{\left[y_{i 1}-\sum_{j \in T_{0}} \widetilde{w}_{i j 0}^{T} y_{j 0}\right]-\left[\sum_{j \in C_{1}} \widetilde{w}_{i j 1}^{C} y_{j 1}-\sum_{j \in C_{0}} \widetilde{w}_{i j 0}^{C} y_{j 0}\right]\right\} w_{i}
$$

where $R C S$ implies repeated cross section, $\left(T_{1}, T_{0}, C_{1}, C_{0}\right)$ stand for the treatment group (RSBY card holders) and control group (non-RSBY) after (2012) and before (2005) the program, and $\widetilde{w}^{G}$ represent the weight attributed to individual $j$ in group $G$ and time $t$ when comparing with the treated individual $i$.

\section{Results}

As discussed in the Data section, many characteristics are different between the RSBY and non RSBY households (Table 3). Table 4 reports the results for the probit model used to obtain the propensity scores. All the explanatory variables are from 2005 data when RSBY was not available, and hence could not been effected by assignment of RSBY. In addition to the covariates reported in Table 4, the probit model also control for district fixed effects. As intended, having below poverty line card increases the probability of household holding

\footnotetext{
${ }^{10}$ The probablity that the same individual recieved medical treatment in both survey years is quite low. This leads to additional problem of defining $\triangle y$ conditional on having recieved medical treatment. Use of repeated cross-section MDID avoid this problem.
} 
RSBY card. Similarly, per capita income and consumption is negatively associated with having RSBY card in rural area, however, both these variables are statistically insignificant in urban areas. Having a casual job increases the probability of having RSBY in rural India as expected, however, it is statistically insignificant in urban areas. The socially disadvantaged group Scheduled Tribe households are more likely to have RSBY in rural areas but not in urban areas. Importantly, there seems little evidence of adverse selection after controlling for economic status. For example, in rural areas none of household health indicators are significant determinant of RSBY card. Moreover, signs of many of the coefficients on the health indicators are negative. These patterns are also visible in urban areas.

Figure 1 shows the kernel density of the propensity scores before matching (the predicted probability of being covered by RSBY as estimated in Table 4) for RSBY households and non-RSBY households for rural and urban area separately. There is considerable overlap of the propensity scores across treatment (RSBY households) and control group (non-RSBY households). The distribution for the non-RSBY households is skewed, with the bulk of cases having a very small probability of being covered. However, given the large sample size of comparison group compared to treatment group (about 7:1), there are plenty of households with larger probabilities of being covered by RSBY but who are not actually covered by the RSBY. We impose the common support in all our matching estimators and do not lose any treatment observations because of lack of control observations.

In the matching literature, there are many methods used to match control observation to treated observations, and there is no consensus about the method of matching. For our main results, we use kernel matching. ${ }^{11}$ Kernel matching defines a neighborhood for each treated observation and constructs the counterfactual using all control observations within the neighborhood weighing each observation based on the distance between the treated and the control being matched, where the weighting function is decreasing in distance. By using more observations per treated, kernel weights reduce the variability of the estimator when

\footnotetext{
${ }^{11}$ We use psmatch2 (Leuven and Sianesi, 2003) in STATA. For kernel matching, the epanechnikov kernel and a fixed bandwidth of 0.10 is used. Confidence intervals are obtained using 50 bootstrap repetitions.
} 
compared with nearest neighbor weights and produces less bias then nearest neighbor with many matches per treated (Blundell and Dias, 2004). However, we also present the results with nearest neighbor matching with five neighbors.

In appendix Table A1, we report the results of the balancing tests for rural and urban areas separately after matching. In urban areas, after matching, difference in only one covariate, indicator for Other Backward Castes, is marginally statistically significant ( $p$ value $=0.048)$. Similarly, in rural areas, after matching except for the two variables, there is no statistically significant differences between RSBY and non-RSBY households. Thus matching does a good job in making the groups comparable, as after matching, there remains very little difference between RSBY and non-RSBY households on the observables. In Table 5, we present alternative measure of effectiveness of matching: the pseudo- $R^{2}$ from the unmatched and matched sample. Matching reduces the pseudo- $R^{2}$ from $0.197(0.175)$ to 0.007 (0.006) in rural (urban) areas. The hypothesis of the joint insignificance of all the regressors cannot be rejected after matching in both rural and urban areas. Hence, propensity score matching does a good job in achieving a comparable control group.

Table 6 presents the MDID estimates for household level indicators. Column (3) of Table 6 presents the ATT estimates as percentage changes on pre-RSBY averages of RSBY households. In rural areas, the RSBY households are 3 percentage points more likely to report any morbidity, and most of this is driven by an increase in reported case for long term morbidity. Probably some of these increases are driven by increased detection of those diseases through improved access to medical facilities for RSBY households. Similar results are reflected in probability of someone in the household seeking treatment. There is no statistically significant impact of RSBY on the probability of a household member receiving treatment for short-term morbidity, however, RSBY households are 4.7 percentage points more likely to report medical treatment for a long-term morbidity. Moreover, although the impact of RSBY on the probability of a household member being hospitalized is positive, its not statistically significant. 
In terms of financial protection, there is no impact of RSBY on the probability of a household reporting any OOP expenditure. There is some evidence that the RSBY reduces household per capita OOP expenditure, however, none of these differences are statistically significant. Importantly the negative impact of RSBY is reflected in out-patient services and not in in-patient services. RSBY covers the hospitalization cost, and hence expected to make a dent in the in-patient OOP expenditures. As Karan et al. (2006) suggest that the prediction of RSBY's effect on outpatient care is ambiguous. It depends on whether out-patient care complements to or substitutes of in-patient care. Nonetheless, there is very little evidence of RSBY effecting either in-patient or out-patient expenditure significantly. Moreover, there is no evidence that RSBY has significant impact on the share of OOP expenditure in total household budget. Similary, there is no impact of RSBY on the probablity of a household incurring catastropic expenditure on health. There is no significant impact of RSBY on the probability of a household taking a loan to meet medical expenses. Similarly, there is no significant impact of RSBY on per capita expenditure on either short-term morbidity or long-term morbidity. It should be noted that RSBY reduces the cost of medicines for the beneficiary households by INR 20 (which is about $30 \%$ of baseline medicine expenditure by RSBY households).

Column (4) and column (6) of Table 6 provide estimates for nearest neighbor matching and fixed effects. The results from nearest neighbor matching are similar to the kernel matching estimates. Importantly, the fixed effects estimates differ from MDID estimates quantitatively. Many of the impact estimates are larger in magnitude and statistically significant. Based on fixed effects estimates, one may conclude that RSBY not only increased utilization but also lower the burden of medical costs on beneficiary households.

Table 7 presents the results for urban India. In urban India, there is no evidence of any impact of RSBY on any indicator except one. Surprisingly, the RSBY households are more likely to take a loan for medical purposes, and the other alternative estimates give similar finding as far as probability of taking a loan to meet medical expenses is concerned. 
The nearest neighborhood estimates are similar to kernel matching estimates. However, the fixed effects estimates provide a very different story about RSBY impact in urban India. Fixed effect estimates suggest that RSBY increased utilization in urban areas and importantly RSBY households spend less compared to non-RSBY households for inpatient and outpatient services. Nevertheless, based on short-term and long-term morbidity costs, fixed effects estimates suggest that RSBY households spend more although the estimates are not statistically significant.

The limited evidence of the impact of RSBY is although unexpected given the negligible cost of enrollment and use of cashless services, however, not out of line with the existing evidence in terms of RSBY and evidence on SHI in other countries. For example, Acharya et al. (2012) review research on 19 health insurance studies across the world and find that enrollment in many schemes is less than expected and they conclude that impacts on utilization in terms of outpatient visits and hospitalization is limited. They also find weak evidence to show that health insurance reduced out-of-pocket health expenses. They find that only four of 16 studies reporting on costs provided conclusive indications of lower average OOP expenditures for the insured. Seven studies provided mixed results, and two showed no effect. Lei and Lin (2009) do not find any significant difference in OOP expenditures for people insured under China's New Cooperative Medical Scheme (NCMS) NCMS. Wagstaff et al. (2009) note weak evidence for lower OOP expenditures for the insured under the NCMS; however, this evidence is sensitive to matching methods.

\subsection{Patient-level results}

Table 8 presents the results of the impact of RSBY conditional on being treated for longterm morbidity. Column (1) of Table 8 presents the estimates of repeated cross-section matching difference-in-difference (RCS MDID). ${ }^{12}$ Column (3) of Table 8 presents the single difference matching estimates for comparison purposes. Conditional on being treated for

\footnotetext{
${ }^{12} \mathrm{RCS}$ MDID is estimated using the stata diff command (Villa, 2016).
} 
long-term morbidity, RSBY increases the probability of a person's (or a patient's) hospitalization by 4.6 percentage points in rural areas. Similarly, the patient with RSBY coverage is 4.2 percentage points more likely to seek advice from a government doctor in rural areas. Importantly, a RSBY patient in rural area spends 124 INR less on medicine which is about $31 \%$ of the baseline expenditure on medicine (INR 402 in 2005). Nonetheless, there is no significant impact of RSBY patient's expenditure on hospitalization and total OOP expenditure (that include cost of medicines, hospitalization and physician fees, and transportation cost). Similarly, there is no impact of RSBY on number of days lost due to long-term morbidity and number of days spent in hospital. The single difference estimates for rural areas suggest a positive impact of RSBY on the probability of a advice sought from government doctor, and reduced expenditure on medicine, which are similar to the findings from RCS MDID estimates. However, the single difference estimator suggest a a much larger and statistically significant reduction in OOP expenditure.

For urban areas, there is no evidence of any impact of RSBY on a patient's utilization of hospital or government doctor. Surprisingly, the direction of impact of RSBY on expenditure on medicine and total OOP expenditure is positive although not statistically significant. The single difference estimates suggest similar conclusion except on the probability of a patient seeking advice from a government doctor.

\section{Conclusion}

The Government of India launched a national health scheme, Rashtriya Swasthya Bima Yojana (RSBY), in 2008 that provides hospitalization coverage up to 30,000 Indian Rupees (INR, 1USD=56 INR as of June. 2012) per annum for a family of five at 30 INR enrollment/renewal cost per family per annum. The unique feature of RSBY is use of smart card and provision of cashless services up to the 30,000 INR limit. Using a nationally representative panel household survey data, we implement difference-in-difference with matching to 
evaluate the impact of RSBY (Average Treatment Impact on the Treated, ATT) on beneficiary households' utilization of health services and expenses incurred.

We find some evidence of positive impact of RSBY on utilization of health services by RSBY households in rural India but not in urban India. The RSBY increased the probability of a household receiving treatment by 3 percentage points in rural areas. However, there is no evidence that the RSBY reduced per person OOP expenditure for RSBY households in both rural and urban areas. There is some evidence that the RSBY reduced expenditure on medicines for beneficiary households in rural India. Conditional on having received medical treatment for major morbidity, we find that RSBY increased probability of hospitalization and being treated by a government doctor in rural areas but no significant impact in urban areas. We also find lower expenditure on medicine for a RSBY cardholder patient in rural areas.

There are some limitations of the findings of this paper. First, the post program data used in the paper was collected in 2011-12, while the RSBY started only in 2008 and was implemented across Indian districts in staggered way. Given the heavy reliance on the demand of the services by beneficiary households under the program, awareness of the benefits available under the program is critical. It is plausible that the impact of the RSBY will be more reflected in evaluation studies as the program matures. Second, we do not consider the impact of the RSBY on direct health outcomes. Third, a weaker implementation and a less responsive supply-side may possibly be driving not statistically significant effect of RSBY on average out-of-pocket spending by households. 


\section{References}

[1] Acharya, A., Vellakkal, S., Taylor, F., Masset, E., Satija, A., Burke, M., and Ebrahim, S. (2012). Impact of health insurance for the informal sector in developing countries: A systematic review. World Bank Research Observer. doi: 10.1093/wbro/lks009

[2] Blundell, R. and Dais, M. C. (2009). Alternative Approaches to Evaluation in Empirical Microeconomics. Journal of Human Resources, 44 (3), 565-640.

[3] Das, J. and Leino, J. (2011). Evaluating the RSBY: Lessons from an experimental information campaign. Economic and Political Weekly, 46(32), 85-93.

[4] Desai, S. and Vanneman, R (2015). India Human Development Survey-II (IHDS-II), 2011-12. ICPSR36151-v2. Ann Arbor, MI: Inter-university Consortium for Political and Social Research [distributor], 2015-07-31. http://doi.org/10.3886/ICPSR36151.v2.

[5] Desai, S., Vanneman, R., and National Council of Applied Economic Research, New Delhi (2010). India Human Development Survey (IHDS), 2005. ICPSR22626-v8. Ann Arbor, MI: Inter-university Consortium for Political and Social Research [distributor], 2010-06-29. http://doi.org/10.3886/ICPSR22626.v8.

[6] Devadasan, N., Seshadri, T., Trivedi, M., and Criel, B. (2013). Promoting universal financial protection: evidence from the Rashtriya Swasthya Bima Yojana (RSBY) in Gujarat, India. Health Research Policy and systems, 11, 1-29.

[7] Gerard, L. F. and Nagpal, S. (2012). Government-Sponsored Health Insurance in India: Are You Covered? The World Bank, Washington DC.

[8] Hsiao, W. and Shaw, R.P. (2007). Social Health Insurance for Developing Nations. The World Bank, Washington DC.

[9] Johnson, D. and Krishnaswamy, K. (2012). The impact of RSBY on hospital utilization and out-of-pocket health expenditure. The World Bank Group, Wash- 
ington, DC. http://documents.worldbank.org/curated/en/2015/08/24144032/impactrsby-hospital-utilization-out-of-pocket-health-expenditure

[10] Karan, A. K., Yip, W. C. M., and Mahal, A. (2015). Extending Health Insurance to the Poor in India: An Impact Evaluation of Rashtriya Swasthya Bima Yojana on Financial Risk Protection (December 11, 2015). SSRN-2702395.

[11] Leuven, E. and Sianesi, B. (2003). PSMATCH2: Stata module to perform full Mahalanobis and propensity score matching, common support graphing, and covariate imbalance testing. http://ideas.repec.org/c/boc/bocode/s432001.html. version 4.0.11 22 oct 2014 .

[12] Ministry of Labour and Employment. (2012). RSBY Connect, Issue No. 11, December 2012.

[13] Nandi, A., Ashok, A., and Laxminarayan, R. (2013). The Socioeconomic and Institutional Determinants of Participation in India's Health Insurance Scheme for the Poor. PLoS ONE, 8(6): e66296. doi:10.1371/journal.pone.0066296.

[14] Rathi, P., Mukherjee, A., and Sen, G. (2012). Rashtriya Swasthya Bima Yojana: Evaluating utilization, roll-out and perception in Amaravati district, Maharashtra. Economic and Political Weekly, 48(39), 57-64.

[15] Raza, W., van de Poel, E., and Panda, P. (2016). Analyses of enrolment, dropout and effectiveness of RSBY in northern rural India. MPRA Working Paper, 70081 (March, 2016).

[16] Rokx, C., Schieber, G., Harimurti, P., Tandon, A., and Somanathan, A. (2009). Health Financing in Indonesia: A Reform Roadmap. The World Bank, Washington, DC.

[17] Swarup, A. and Jain, A. (2011). Rashtriya Swasthya Bima Yojana. In Sharing Innovative Experiences, UNDP. 
[18] UNDP. (2011). Sharing Innovative Experiences: Successful Social Protection Floor Experiences. Volume 18 of series Sharing Innovative Experiences, UNDP.

[19] Villa, J. M. (2016). diff: Simplifying the estimation of difference-in-differences treatment effects, Stata Journal, 16(1), 52-71.

[20] Wagstaff, A., Lindelow, M., Jun, G., Ling, X., and Juncheng, Q. (2009). Extending health insurance to the rural population: An impact evaluation of China's New Cooperative Medical Scheme. Journal of Health Economics, 2009, 28(1), 1-19.

[21] WHO. (2010). The World health report 2000 : health systems : improving performance. World Health Organization. 
Figure 1: Overlap region
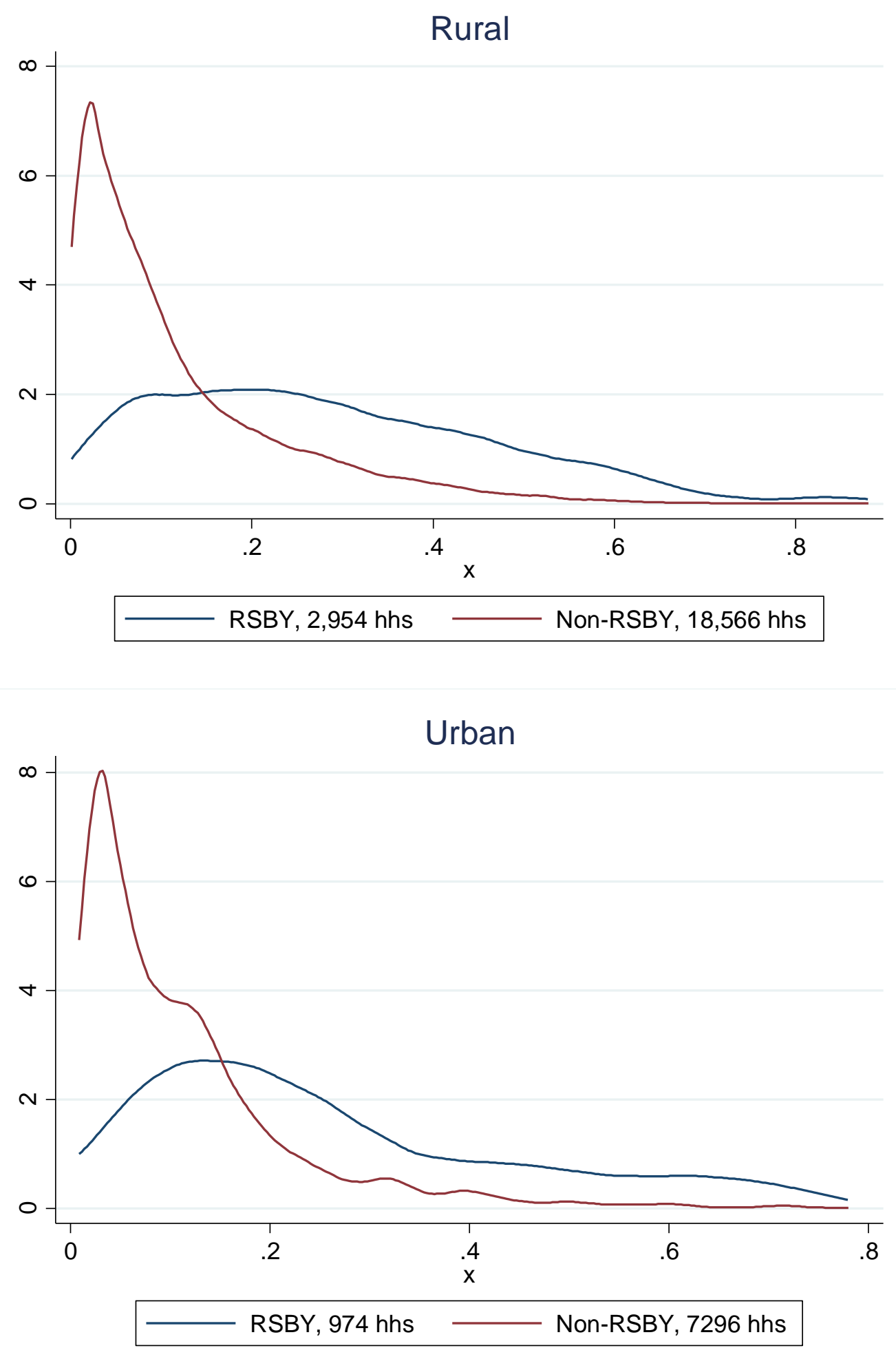
Table-1: Descriptive statistics for outcomes at household-level

\begin{tabular}{|c|c|c|c|c|c|c|}
\hline \multirow[t]{2}{*}{ Rural } & \multicolumn{3}{|c|}{ 2011-12 } & \multicolumn{3}{|c|}{ 2004-05 } \\
\hline & RSBY & Non-RSBY & Difference & RSBY & Non-RSBY & Difference \\
\hline Household reporting any illness & 0.783 & 0.738 & $0.045^{* * *}$ & 0.668 & 0.632 & $0.037 * * *$ \\
\hline Household reporting any short term (ST) illness & 0.618 & 0.599 & $0.019 * *$ & 0.563 & 0.536 & $0.027^{* * *}$ \\
\hline Household reporting any long term (LT) illness & 0.477 & 0.396 & $0.081 * * *$ & 0.284 & 0.253 & $0.032 * * *$ \\
\hline Household reporting any treatment & 0.762 & 0.714 & $0.048 * * *$ & 0.638 & 0.604 & $0.034 * * *$ \\
\hline Household reporting treatment for ST morbidity & 0.607 & 0.582 & $0.025^{* * *}$ & 0.534 & 0.511 & $0.023 * *$ \\
\hline Household reporting treatment for LT morbidity & 0.437 & 0.364 & $0.073 * * *$ & 0.261 & 0.232 & $0.029 * * *$ \\
\hline Household reported hospitalization for LT morbidity & 0.059 & 0.046 & $0.012^{* * *}$ & 0.039 & 0.032 & $0.007 * *$ \\
\hline Household reported out-of-pocket (OOP) expenditure & 0.802 & 0.804 & -0.002 & 0.714 & 0.709 & 0.005 \\
\hline Per capita inpatient expenditure in INR at 2012 prices & 91.689 & 103.213 & -11.524 & 59.423 & 59.197 & 0.226 \\
\hline Per capita outpatient expenditure in INR at 2012 prices & 109.907 & 107.524 & 2.382 & 94.694 & 88.201 & 6.493 \\
\hline Per capita total OOP in INR at 2012 prices & 201.521 & 210.617 & -9.096 & 153.960 & 147.278 & 6.682 \\
\hline Share of OOP in household monthly expenditure & 0.107 & 0.097 & $0.010^{* * *}$ & 0.097 & 0.085 & $0.012^{* * *}$ \\
\hline Catastrophic medical expenditure & 0.216 & 0.189 & $0.027^{* * *}$ & 0.193 & 0.161 & $0.032 * * *$ \\
\hline Household took loan to meet medical expenses & 0.132 & 0.090 & $0.042 * * *$ & 0.086 & 0.060 & $0.026 * * *$ \\
\hline Per capita expenditure on ST morbidity & 114.323 & 110.806 & 3.517 & 83.858 & 73.050 & $10.809 * *$ \\
\hline Per capita expenditure on LT morbidity & 105.462 & 111.831 & -6.370 & 47.789 & 49.136 & -1.346 \\
\hline Per capita expenditure on medicines & 107.352 & 110.773 & -3.421 & 69.292 & 55.867 & $13.425^{* * *}$ \\
\hline Per capita expenditure on hospital and doctors & 99.246 & 99.154 & 0.092 & 27.953 & 30.192 & -2.239 \\
\hline Per capita total OOP from individual modules & 219.785 & 222.638 & -2.853 & 131.648 & 122.185 & 9.462 \\
\hline Number of households & 2954 & 18563 & & 2954 & 18566 & \\
\hline \multirow[t]{2}{*}{ Urban } & \multicolumn{3}{|c|}{ 2011-12 } & \multicolumn{3}{|c|}{ 2004-05 } \\
\hline & RSBY & Non-RSBY & Difference & RSBY & Non-RSBY & Difference \\
\hline Household reporting any illness & 0.761 & 0.731 & $0.030 * *$ & 0.613 & 0.581 & $0.032 *$ \\
\hline Household reporting any short term (ST) illness & 0.522 & 0.534 & -0.013 & 0.452 & 0.437 & 0.015 \\
\hline Household reporting any long term (LT) illness & 0.500 & 0.455 & $0.045^{* * *}$ & 0.305 & 0.289 & 0.016 \\
\hline Household reporting any treatment & 0.743 & 0.716 & $0.027^{*}$ & 0.590 & 0.561 & $0.029 *$ \\
\hline Household reporting treatment for ST morbidity & 0.511 & 0.522 & -0.011 & 0.431 & 0.417 & 0.014 \\
\hline Household reporting treatment for LT morbidity & 0.471 & 0.434 & $0.037 * *$ & 0.290 & 0.275 & 0.015 \\
\hline Household reported hospitalization for LT morbidity & 0.078 & 0.055 & $0.023 * * *$ & 0.045 & 0.032 & $0.013^{* *}$ \\
\hline Household reported out-of-pocket (OOP) expenditure & 0.752 & 0.791 & $-0.040 * * *$ & 0.666 & 0.648 & 0.019 \\
\hline Per capita inpatient expenditure in INR at 2012 prices & 125.275 & 125.953 & -0.678 & 79.731 & 68.783 & 10.949 \\
\hline Per capita outpatient expenditure in INR at 2012 prices & 87.989 & 111.526 & $-23.537 * *$ & 70.333 & 86.309 & -15.976 \\
\hline Per capita total OOP in INR at 2012 prices & 212.608 & 237.286 & -24.678 & 149.602 & 154.645 & -5.043 \\
\hline Share of OOP in household monthly expenditure & 0.070 & 0.072 & -0.002 & 0.073 & 0.065 & $0.008 * *$ \\
\hline Catastrophic medical expenditure & 0.128 & 0.129 & -0.001 & 0.133 & 0.116 & 0.017 \\
\hline Household took loan to meet medical expenses & 0.082 & 0.064 & $0.018^{* *}$ & 0.041 & 0.040 & 0.001 \\
\hline Per capita expenditure on ST morbidity & 74.212 & 76.888 & -2.675 & 45.121 & 49.076 & -3.954 \\
\hline Per capita expenditure on LT morbidity & 161.585 & 136.110 & 25.475 & 54.043 & 58.350 & -4.307 \\
\hline Per capita expenditure on medicines & 140.212 & 121.809 & 18.403 & 48.545 & 54.059 & -5.514 \\
\hline Per capita expenditure on hospital and doctors & 83.057 & 82.439 & 0.618 & 25.271 & 27.543 & -2.272 \\
\hline Per capita total OOP from individual modules & 235.797 & 212.998 & 22.799 & 99.165 & 107.426 & -8.261 \\
\hline Number of households & 974 & 7296 & & 974 & 7296 & \\
\hline
\end{tabular}

Note: All expenditures are monthly expenditures in Indian Rupees (INR) at 2012 prices. ${ }^{* * *} p<0.01,{ }^{* *} p<0.05,{ }^{*} p<0.1$ 
Table 2: Descriptive statistics for outcomes at patient level for long-term morbidity treatment

\begin{tabular}{|c|c|c|c|c|c|c|}
\hline \multirow[b]{3}{*}{ Rural } & \multicolumn{3}{|c|}{ 2011-12 } & \multicolumn{3}{|c|}{ 2004-05 } \\
\hline & RSBY & Non-RSBY & Difference & RSBY & Non-RSBY & Difference \\
\hline & & & & & & \\
\hline Hospitalized & 0.270 & 0.256 & 0.014 & 0.286 & 0.308 & -0.022 \\
\hline Treated by government doctor & 0.317 & 0.230 & $0.087^{* * *}$ & 0.301 & 0.244 & $0.057 * * *$ \\
\hline Expenditure on medicines in INR & 546.511 & 759.767 & $-213.255^{* * *}$ & 402.867 & 430.344 & -27.477 \\
\hline Expenditure on hospital in INR & 86.997 & 127.531 & $-40.534 * * *$ & 129.697 & 178.673 & -48.976 \\
\hline Total out-of-pocket in INR & 842.038 & 1092.204 & $-250.166^{* * *}$ & 782.452 & 988.756 & $-206.304 * *$ \\
\hline Days lost & 47.818 & 44.877 & 2.941 & 54.259 & 61.563 & $-7.304^{*}$ \\
\hline Days in hospital & 2.877 & 3.062 & -0.185 & 4.426 & 4.160 & 0.266 \\
\hline Observations & 1641 & 8489 & & 787 & 3981 & \\
\hline \multicolumn{7}{|l|}{ Urban } \\
\hline Hospitalized & 0.253 & 0.222 & $0.031^{*}$ & 0.326 & 0.242 & $0.084 * * *$ \\
\hline Treated by government doctor & 0.334 & 0.213 & $0.121 * * *$ & 0.378 & 0.246 & $0.132 * * *$ \\
\hline Expenditure on medicines in INR & 812.349 & 683.906 & 128.443 & 368.269 & 394.070 & -25.802 \\
\hline Expenditure on hospital in INR & 111.116 & 110.768 & 0.348 & 158.064 & 119.735 & 38.329 \\
\hline Total out-of-pocket in INR & 1162.699 & 1003.935 & 158.764 & 779.970 & 800.804 & -20.834 \\
\hline Days lost & 34.361 & 34.930 & -0.569 & 44.606 & 46.025 & -1.420 \\
\hline Days in hospital & 3.189 & 2.308 & $0.881 * * *$ & 6.130 & 3.228 & $2.902 * * *$ \\
\hline Observations & 604 & 4052 & & 307 & 2119 & \\
\hline
\end{tabular}


Table-3: Household characteristics in 2004-05

\begin{tabular}{|c|c|c|c|c|c|c|}
\hline & \multicolumn{3}{|c|}{ Rural } & \multicolumn{3}{|c|}{ Urban } \\
\hline & $\begin{array}{c}\text { RSBY } \\
\text { households }\end{array}$ & $\begin{array}{l}\text { Non-RSBY } \\
\text { households }\end{array}$ & Difference & $\begin{array}{c}\text { RSBY } \\
\text { households }\end{array}$ & $\begin{array}{l}\text { Non-RSBY } \\
\text { households }\end{array}$ & Difference \\
\hline Other Backward Castes+ & 0.334 & 0.330 & 0.004 & 0.330 & 0.243 & $0.087 * * *$ \\
\hline Scheduled Castes+ & 0.277 & 0.226 & $0.051^{* * *}$ & 0.159 & 0.182 & $-0.023^{*}$ \\
\hline Scheduled Tribes+ & 0.112 & 0.102 & 0.010 & 0.032 & 0.036 & -0.004 \\
\hline Muslim+ & 0.089 & 0.095 & -0.006 & 0.152 & 0.171 & -0.019 \\
\hline Household Size & 5.981 & 6.281 & $-0.299 * * *$ & 5.520 & 5.511 & 0.009 \\
\hline Household Size Square & 43.871 & 50.115 & $-6.244 * * *$ & 36.520 & 37.065 & -0.546 \\
\hline$\%$ of age $0-14$ in $\mathrm{HH}$ & 0.325 & 0.308 & $0.018^{* * *}$ & 0.269 & 0.261 & 0.008 \\
\hline$\%$ of age 61 and above in $\mathrm{HH}$ & 0.074 & 0.077 & -0.003 & 0.059 & 0.066 & -0.007 \\
\hline$\%$ of age $15-49$ female in $\mathrm{HH}$ & 0.246 & 0.249 & -0.003 & 0.279 & 0.278 & 0.001 \\
\hline log per capita consumption & 6.841 & 6.994 & $-0.153 * * *$ & 7.294 & 7.381 & $-0.087 * * *$ \\
\hline log of per capita income & 8.906 & 9.031 & $-0.125 * * *$ & 9.672 & 9.792 & $-0.121 * * *$ \\
\hline No ration card+ & 0.123 & 0.123 & -0.001 & 0.144 & 0.154 & -0.011 \\
\hline BPL card+ & 0.386 & 0.281 & $0.105^{* * *}$ & 0.270 & 0.153 & $0.117 * * *$ \\
\hline Poort & 0.314 & 0.228 & $0.086 * * *$ & 0.271 & 0.202 & $0.069 * * *$ \\
\hline Head age & 47.962 & 48.739 & $-0.777 * * *$ & 47.898 & 47.814 & 0.084 \\
\hline Head is female+ & 0.092 & 0.084 & 0.008 & 0.112 & 0.106 & 0.006 \\
\hline Head's education & 4.035 & 4.237 & $-0.202 * *$ & 6.963 & 7.558 & $-0.595 * * *$ \\
\hline Head's work type-casual+ & 0.555 & 0.427 & $0.128 * * *$ & 0.369 & 0.309 & $0.060 * * *$ \\
\hline Head's work-type-government+ & 0.045 & 0.060 & $-0.015^{* * *}$ & 0.189 & 0.177 & 0.011 \\
\hline Per capita inpatient expenditure & 59.423 & 59.197 & 0.226 & 79.731 & 68.783 & 10.949 \\
\hline Per capita outpatient expenditure & 94.694 & 88.201 & 6.493 & 70.333 & 86.309 & -15.976 \\
\hline$\%$ of members reported- fever & 0.142 & 0.124 & $0.018 * * *$ & 0.108 & 0.095 & $0.012^{* *}$ \\
\hline$\%$ of members reported- cough & 0.113 & 0.100 & $0.014 * * *$ & 0.083 & 0.083 & 0.000 \\
\hline$\%$ of members reported- diarrhea & 0.041 & 0.033 & $0.009 * * *$ & 0.021 & 0.021 & 0.000 \\
\hline $\begin{array}{l}\% \text { of members reported- short term (ST) problems } \\
\% \text { of members reported- received treatment for ST }\end{array}$ & 0.159 & 0.142 & $0.017^{* * *}$ & 0.122 & 0.115 & 0.007 \\
\hline problems & 0.148 & 0.134 & $0.015^{* * *}$ & 0.114 & 0.107 & 0.006 \\
\hline$\%$ of members reported- government doctor for ST & 0.034 & 0.027 & $0.007 * * *$ & 0.025 & 0.019 & $0.007^{* *}$ \\
\hline$\%$ of members reported- private doctor for ST problem & 0.103 & 0.096 & $0.007 * *$ & 0.076 & 0.075 & 0.001 \\
\hline$\%$ of members reported- long term (LT) problems & 0.068 & 0.057 & $0.011 * * *$ & 0.076 & 0.075 & 0.001 \\
\hline$\%$ of members reported- cataract & 0.007 & 0.006 & $0.002^{*}$ & 0.003 & 0.004 & -0.001 \\
\hline$\%$ of members reported- tuberculosis & 0.004 & 0.003 & 0.001 & 0.003 & 0.002 & 0.001 \\
\hline$\%$ of members reported- blood pressure & 0.014 & 0.008 & $0.005 * * *$ & 0.023 & 0.024 & 0.000 \\
\hline$\%$ of members reported- heart disease & 0.005 & 0.003 & $0.001^{*}$ & 0.007 & 0.009 & -0.002 \\
\hline$\%$ of members reported- diabetes & 0.008 & 0.004 & $0.004^{* * *}$ & 0.014 & 0.012 & 0.002 \\
\hline$\%$ of members reported- leprosy & 0.001 & 0.001 & $0.001 * *$ & 0.001 & 0.001 & 0.000 \\
\hline$\%$ of members reported- cancer & 0.000 & 0.001 & 0.000 & 0.001 & 0.001 & -0.001 \\
\hline$\%$ of members reported- asthma & 0.008 & 0.007 & $0.002^{*}$ & 0.005 & 0.006 & 0.000 \\
\hline$\%$ of members reported-polio & 0.001 & 0.001 & 0.000 & 0.001 & 0.001 & 0.000 \\
\hline Per capita hospital days & 0.256 & 0.211 & 0.045 & 0.550 & 0.239 & $0.311^{* * *}$ \\
\hline Per capita days lost in illness & 4.232 & 3.982 & 0.250 & 3.655 & 3.690 & -0.035 \\
\hline $\mathrm{HH}$ has piped water access+ & 0.205 & 0.248 & $-0.043^{* * *}$ & 0.682 & 0.673 & 0.009 \\
\hline $\mathrm{HH}$ has hand pump water access+ & 0.400 & 0.429 & $-0.029 * * *$ & 0.133 & 0.177 & $-0.043 * * *$ \\
\hline $\mathrm{HH}$ has no access to toilet+ & 0.725 & 0.707 & $0.017^{*}$ & 0.294 & 0.239 & $0.055^{* * *}$ \\
\hline HH has no electricity+ & 0.396 & 0.326 & $0.070 * * *$ & 0.072 & 0.055 & $0.017^{* *}$ \\
\hline
\end{tabular}




\begin{tabular}{|c|c|c|c|c|c|c|}
\hline House building in poor conditions+ & 0.189 & 0.177 & 0.011 & 0.167 & 0.136 & $0.032 * * *$ \\
\hline $\mathrm{HH}$ have health insurance+ & 0.018 & 0.019 & -0.001 & 0.039 & 0.047 & -0.008 \\
\hline HH use radio+ & 0.133 & 0.130 & 0.003 & 0.111 & 0.121 & -0.010 \\
\hline HH use paper+ & 0.127 & 0.124 & 0.003 & 0.428 & 0.408 & 0.020 \\
\hline HH use Television+ & 0.215 & 0.266 & $-0.050 * * *$ & 0.574 & 0.573 & 0.001 \\
\hline HH know some doctor+ & 0.313 & 0.298 & $0.016^{*}$ & 0.355 & 0.375 & -0.020 \\
\hline HH know some teacher+ & 0.374 & 0.383 & -0.009 & 0.437 & 0.422 & 0.015 \\
\hline HH know some government servant+ & 0.260 & 0.290 & $-0.030 * * *$ & 0.413 & 0.445 & $-0.033^{*}$ \\
\hline HH suffered death in last year+ & 0.052 & 0.047 & 0.005 & 0.022 & 0.037 & $-0.015^{* *}$ \\
\hline Confidence in hospital/doctors & 0.637 & 0.673 & $-0.036 * * *$ & 0.686 & 0.605 & $0.081 * * *$ \\
\hline Great deal of confidence in state govt & 0.280 & 0.275 & 0.005 & 0.260 & 0.230 & $0.029 * *$ \\
\hline Large village-5000 population+ & 0.252 & 0.172 & $0.080 * * *$ & & & \\
\hline Distance to town in $\mathrm{km}$ & 14.390 & 13.399 & $0.991 * * *$ & & & \\
\hline Distant to district $\mathrm{HQ}$ in $\mathrm{km}$ & 41.968 & 42.356 & -0.388 & & & \\
\hline No access to surfaced road+ & 0.887 & 0.925 & $-0.037 * * *$ & & & \\
\hline No bus stop in village+ & 0.519 & 0.489 & $0.029 * * *$ & & & \\
\hline Number of anganwadis in village & 3.206 & 2.284 & $0.921 * * *$ & & & \\
\hline Health sub center in village+ & 0.374 & 0.393 & $-0.019 *$ & & & \\
\hline Primary health center in village+ & 0.174 & 0.132 & $0.041^{* * *}$ & & & \\
\hline Village have trained private doctor+ & 0.227 & 0.232 & -0.005 & & & \\
\hline Number of Households & 2954 & 18556 & & 974 & 7296 & \\
\hline
\end{tabular}




\begin{tabular}{|c|c|c|c|c|}
\hline \multirow[t]{3}{*}{ Dependent variable: HH has RSBY in 2011} & \multirow{2}{*}{\multicolumn{4}{|c|}{ Urban }} \\
\hline & & & & \\
\hline & \multirow{2}{*}{$\begin{array}{c}(1) \\
\text { coef }\end{array}$} & \multirow{2}{*}{$\begin{array}{l}(2) \\
\text { se }\end{array}$} & \multirow{2}{*}{$\begin{array}{c}(3) \\
\text { coef }\end{array}$} & \multirow{2}{*}{$\begin{array}{l}\text { (4) } \\
\text { se }\end{array}$} \\
\hline Household correlates in 2005 & & & & \\
\hline Other Backward Castes+ & 0.011 & $(0.055)$ & -0.008 & $(0.060)$ \\
\hline Scheduled Castes+ & $0.167 * * *$ & $(0.057)$ & -0.117 & $(0.072)$ \\
\hline Scheduled Tribes+ & -0.003 & $(0.080)$ & 0.178 & $(0.155)$ \\
\hline Muslim+ & $0.123^{*}$ & $(0.072)$ & $-0.175^{* *}$ & $(0.078)$ \\
\hline Household Size & $0.034^{*}$ & $(0.019)$ & 0.032 & $(0.030)$ \\
\hline Household Size Square & $-0.002 *$ & $(0.001)$ & -0.001 & $(0.002)$ \\
\hline$\%$ of age $0-14$ in $\mathrm{HH}$ & 0.009 & $(0.108)$ & 0.104 & $(0.145)$ \\
\hline$\%$ of age 61 and above in $\mathrm{HH}$ & -0.144 & $(0.133)$ & -0.298 & $(0.202)$ \\
\hline$\%$ of age $15-49$ female in $\mathrm{HH}$ & $-0.289 * *$ & $(0.136)$ & 0.140 & $(0.182)$ \\
\hline log per capita consumption & $-0.141 * *$ & $(0.055)$ & 0.045 & $(0.063)$ \\
\hline log of per capita income & $-0.034 * *$ & $(0.014)$ & -0.027 & $(0.018)$ \\
\hline No ration card+ & $-0.118 * *$ & $(0.059)$ & 0.060 & (0.069) \\
\hline BPL card+ & $0.123 * * *$ & $(0.041)$ & $0.283^{* * *}$ & $(0.062)$ \\
\hline Poor+ & -0.031 & $(0.055)$ & -0.015 & $(0.071)$ \\
\hline Head age & $-0.003 *$ & $(0.002)$ & 0.001 & $(0.003)$ \\
\hline Head is female+ & -0.013 & $(0.066)$ & -0.009 & $(0.077)$ \\
\hline Head's education & -0.006 & $(0.005)$ & $-0.018 * * *$ & $(0.006)$ \\
\hline Head's work type-casual+ & $0.144 * * *$ & $(0.041)$ & -0.052 & $(0.054)$ \\
\hline Head's work-type-government+ & -0.069 & $(0.081)$ & $0.158^{* *}$ & $(0.066)$ \\
\hline Per capita inpatient expenditure & 0.000 & $(0.000)$ & 0.000 & $(0.000)$ \\
\hline Per capita outpatient expenditure & -0.000 & $(0.000)$ & $-0.000 *$ & $(0.000)$ \\
\hline$\%$ of members reported- fever & 0.066 & $(0.253)$ & 0.045 & $(0.342)$ \\
\hline$\%$ of members reported- cough & -0.153 & $(0.166)$ & 0.042 & $(0.277)$ \\
\hline$\%$ of members reported- diarrhea & -0.123 & $(0.190)$ & 0.409 & $(0.313)$ \\
\hline$\%$ of members reported- short term (ST) problems & 0.197 & $(0.345)$ & 0.215 & $(0.532)$ \\
\hline$\%$ of members reported- received treatment for ST problems & -0.035 & $(0.347)$ & -0.103 & (0.509) \\
\hline$\%$ of members reported- government doctor for ST & -0.043 & $(0.291)$ & 0.089 & $(0.428)$ \\
\hline$\%$ of members reported- private doctor for ST problem & -0.064 & $(0.255)$ & 0.087 & (0.358) \\
\hline$\%$ of members reported- long term (LT) problems & -0.077 & $(0.197)$ & 0.076 & $(0.234)$ \\
\hline$\%$ of members reported- cataract & -0.226 & $(0.411)$ & -0.649 & $(0.691)$ \\
\hline$\%$ of members reported- tuberculosis & 0.019 & $(0.485)$ & 0.790 & $(0.783)$ \\
\hline$\%$ of members reported- blood pressure & 0.347 & $(0.310)$ & -0.073 & (0.314) \\
\hline$\%$ of members reported- heart disease & 0.481 & $(0.487)$ & -0.047 & (0.516) \\
\hline$\%$ of members reported- diabetes & -0.254 & $(0.396)$ & -0.118 & $(0.378)$ \\
\hline$\%$ of members reported- leprosy & -1.047 & $(1.201)$ & 0.075 & $(0.914)$ \\
\hline$\%$ of members reported- cancer & -1.100 & $(1.201)$ & $-3.441^{*}$ & $(1.960)$ \\
\hline$\%$ of members reported- asthma & 0.277 & $(0.366)$ & 0.373 & $(0.626)$ \\
\hline$\%$ of members reported- polio & -0.477 & $(0.806)$ & -1.965 & $(1.784)$ \\
\hline Per capita hospital days & -0.004 & $(0.010)$ & $0.012^{*}$ & $(0.006)$ \\
\hline Per capita days lost in illness & 0.000 & $(0.001)$ & -0.002 & $(0.002)$ \\
\hline HH has piped water access+ & 0.067 & $(0.058)$ & 0.018 & $(0.072)$ \\
\hline
\end{tabular}




\begin{tabular}{|c|c|c|c|c|}
\hline $\mathrm{HH}$ has hand pump water access+ & 0.056 & $(0.049)$ & -0.142 & (0.099) \\
\hline HH has no access to toilet+ & 0.076 & $(0.055)$ & 0.090 & $(0.063)$ \\
\hline HH has no electricity+ & $0.092^{*}$ & $(0.048)$ & 0.027 & $(0.097)$ \\
\hline House building in poor conditions+ & -0.033 & $(0.052)$ & 0.091 & $(0.070)$ \\
\hline $\mathrm{HH}$ have health insurance+ & -0.072 & $(0.121)$ & -0.064 & (0.119) \\
\hline HH use radio+ & 0.048 & $(0.054)$ & $-0.127^{*}$ & $(0.072)$ \\
\hline HH use paper+ & -0.055 & (0.069) & $0.109 *$ & $(0.058)$ \\
\hline HH use Television+ & -0.052 & $(0.050)$ & -0.021 & $(0.052)$ \\
\hline HH know some doctor+ & -0.035 & (0.049) & 0.014 & $(0.057)$ \\
\hline HH know some teacher+ & 0.025 & $(0.046)$ & 0.040 & $(0.058)$ \\
\hline HH know some government servant+ & 0.046 & $(0.047)$ & -0.070 & $(0.055)$ \\
\hline HH suffered death in last year+ & 0.008 & $(0.078)$ & $-0.252^{*}$ & $(0.144)$ \\
\hline Confidence in hospital and doctors & -0.042 & $(0.040)$ & 0.060 & $(0.050)$ \\
\hline Great deal of confidence in state govt & 0.021 & $(0.042)$ & 0.079 & $(0.054)$ \\
\hline Large village-5000 population+ & $-0.116^{*}$ & $(0.063)$ & & \\
\hline Distance to town in $\mathrm{km}$ & $-0.003^{*}$ & $(0.002)$ & & \\
\hline Distant to district $\mathrm{HQ}$ in $\mathrm{km}$ & -0.001 & $(0.001)$ & & \\
\hline No access to surfaced roadt & 0.021 & $(0.084)$ & & \\
\hline No bus stop in village+ & $0.122 * * *$ & $(0.042)$ & & \\
\hline Number of anganwadis in village & -0.007 & $(0.006)$ & & \\
\hline Health sub center in village+ & 0.031 & $(0.042)$ & & \\
\hline Primary health center in village+ & 0.028 & $(0.067)$ & & \\
\hline Village have trained private doctor+ & $-0.100 *$ & $(0.052)$ & & \\
\hline Constant & -0.356 & $(0.521)$ & $-2.169 * * *$ & $(0.621)$ \\
\hline Observations & 20,847 & & 7,639 & \\
\hline Pseudo-R2 & 0.197 & & 0.175 & \\
\hline
\end{tabular}

Note: + implies indicator variable. Robust standard errors in parentheses. The models also include district fixed effects not reported in Table.

$* * * p<0.01,{ }^{* *} p<0.05, * p<0.1$ 
Table 5: Reduction in bias on observables

\begin{tabular}{lcc}
\hline & Rural & Urban \\
Before matching pseudo- $R^{2}$ & 0.197 & 0.175 \\
Prob > chi2 & 0.000 & 0.000 \\
After matching pseudo- $R^{2}$ & 0.007 & 0.006 \\
Prob > chi2 & 0.779 & 0.711 \\
\hline
\end{tabular}


Table 6: Impact of RSBY, Rural India

\begin{tabular}{|c|c|c|c|c|c|c|c|}
\hline & \multicolumn{2}{|c|}{ Kernel matching } & \multirow{2}{*}{$\begin{array}{c}\text { ATT as \% } \\
\text { of RSBY } \\
\text { households" } \\
2005 \\
\text { average }\end{array}$} & \multicolumn{2}{|c|}{ NN Matching } & \multicolumn{2}{|c|}{ Fixed-effects } \\
\hline & ATT & SE (ATT) & & ATT & $\begin{array}{c}S E \\
(A T T)\end{array}$ & ATT & $\begin{array}{c}S E \\
(A T T)\end{array}$ \\
\hline & (1) & (2) & (3) & (4) & (5) & (6) & (7) \\
\hline Household reporting any illness & $0.030 * *$ & $(0.014)$ & $4.5 \%$ & $0.039 * *$ & $(0.019)$ & $0.046 * *$ & (0.019) \\
\hline Household reporting any short term (ST) illness & 0.008 & $(0.015)$ & $1.6 \%$ & 0.020 & $(0.018)$ & 0.021 & $(0.014)$ \\
\hline Household reporting any long term (LT) illness & $0.048 * * *$ & $(0.013)$ & $16.6 \%$ & $0.043 * * *$ & $(0.014)$ & $0.027^{* * *}$ & (0.009) \\
\hline Household reporting any treatment & $0.028^{* *}$ & $(0.013)$ & $4.3 \%$ & $0.037^{*}$ & $(0.019)$ & $0.041^{* *}$ & (0.019) \\
\hline Household reporting treatment for ST morbidity & 0.013 & $(0.017)$ & $2.6 \%$ & 0.021 & $(0.016)$ & $0.025^{*}$ & $(0.014)$ \\
\hline Household reporting treatment for LT morbidity & $0.048 * * *$ & $(0.012)$ & $18.1 \%$ & $0.046 * * *$ & $(0.015)$ & 0.015 & $(0.011)$ \\
\hline Household reported hospitalization for LT morbidity & 0.008 & $(0.008)$ & $20.0 \%$ & 0.005 & $(0.007)$ & -0.003 & $(0.006)$ \\
\hline Household reported out-of-pocket (OOP) expenditure & 0.005 & $(0.015)$ & $0.6 \%$ & 0.008 & $(0.015)$ & -0.010 & $(0.011)$ \\
\hline Per capita inpatient expenditure in INR & -1.180 & $(12.081)$ & $-2.4 \%$ & 2.869 & $(18.027)$ & $-31.348^{* * *}$ & $(10.307)$ \\
\hline Per capita outpatient expenditure in INR & -15.864 & $(10.841)$ & $-17.1 \%$ & -18.209 & $(11.630)$ & -15.247 & $(9.936)$ \\
\hline Per capita total OOP in INR & -17.044 & $(16.284)$ & $-11.4 \%$ & -15.337 & $(19.920)$ & $-46.394 * * *$ & $(14.130)$ \\
\hline Share of OOP in household monthly expenditure & 0.000 & $(0.004)$ & $-0.3 \%$ & -001 & $(0.005)$ & $-0.007 * *$ & $(0.003)$ \\
\hline Catastrophic medical expenditure & 0.004 & $(0.013)$ & $2.2 \%$ & 0.003 & $(0.014)$ & -0.016 & $(0.011)$ \\
\hline Household took loan to meet medical expenses & 0.010 & $(0.010)$ & $10.9 \%$ & 0.014951 & $(0.011)$ & $0.017^{* *}$ & $(0.008)$ \\
\hline Per capita expenditure on ST morbidity & -7.435 & $(8.998)$ & $-8.7 \%$ & -2.24755 & (14.418) & -47.357 & $(40.813)$ \\
\hline Per capita expenditure on LT morbidity & -3.464 & $(14.405)$ & $-8.5 \%$ & -9.3689 & $(19.699)$ & $-65.341^{*}$ & (34.623) \\
\hline Per capita expenditure on medicines & $-20.364 * *$ & $(9.194)$ & $-29.9 \%$ & -11.6165 & $(15.900)$ & $-121.126 * * *$ & $(36.977)$ \\
\hline Per capita expenditure on hospital and doctors & 4.736 & $(10.371)$ & $16.7 \%$ & 6.041 & $(12.084)$ & 34.316 & $(29.330)$ \\
\hline Per capita total OOP from individual modules & -11.381 & $(14.968)$ & $-8.6 \%$ & -12.550 & $(18.868)$ & $-112.697 * *$ & $(53.066)$ \\
\hline
\end{tabular}

Note: Standard errors are in the parenthesis. For matching, standard errors are derived through bootstrap with 50 replications. Fixed effects standard errors are clustered at household level. ${ }^{* *} p<0.01, * * p<0.05, * p<0.1$ 
Table 7: Impact of RSBY, Urban India

\begin{tabular}{|c|c|c|c|c|c|c|c|}
\hline & \multicolumn{2}{|c|}{ Kernel matching } & \multirow{2}{*}{$\begin{array}{c}\text { ATT as \% } \\
\text { of RSBY } \\
\text { households' } \\
2005 \\
\text { average }\end{array}$} & \multicolumn{2}{|c|}{ NN matching } & \multicolumn{2}{|c|}{ Fixed effects } \\
\hline & ATT & SE (ATT) & & $A T T$ & SE (ATT) & ATT & SE (ATT) \\
\hline & (1) & $(2)$ & (3) & (4) & (5) & (6) & (7) \\
\hline Household reporting any illness & 0.017 & $(0.025)$ & $2.8 \%$ & 0.013 & $(0.033)$ & $0.079 * * *$ & $(0.025)$ \\
\hline Household reporting any short term (ST) illness & -0.009 & $(0.026)$ & $-1.9 \%$ & -0.022 & $(0.030)$ & $0.036 * *$ & $(0.018)$ \\
\hline Household reporting any long term (LT) illness & 0.019 & $(0.024)$ & $6.3 \%$ & 0.016 & $(0.028)$ & $0.043 * * *$ & $(0.015)$ \\
\hline Household reporting any treatment & 0.017 & $(0.027)$ & $2.8 \%$ & 0.014 & $(0.031)$ & $0.060 * *$ & $(0.025)$ \\
\hline Household reporting treatment for ST morbidity & -0.010 & $(0.024)$ & $-2.2 \%$ & -0.018 & (0.029) & $0.031 *$ & $(0.018)$ \\
\hline Household reporting treatment for LT morbidity & 0.012 & $(0.025)$ & $4.0 \%$ & 0.005 & $(0.028)$ & 0.021 & $(0.017)$ \\
\hline Household reported hospitalization for LT morbidity & 0.012 & $(0.015)$ & $26.1 \%$ & 0.027 & $(0.016)$ & 0.003 & $(0.011)$ \\
\hline Household reported out-of-pocket (OOP) expenditure & -0.032 & $(0.024)$ & $-4.9 \%$ & -0.033 & $(0.030)$ & -0.031 & $(0.019)$ \\
\hline Per capita inpatient expenditure in INR & -5.449 & $(26.961)$ & $-6.8 \%$ & -4.211 & $(35.323)$ & $-43.223^{*}$ & $(25.958)$ \\
\hline Per capita outpatient expenditure in INR & -9.357 & $(10.743)$ & $-13.3 \%$ & -14.641 & $(14.917)$ & $-20.043 * *$ & $(9.400)$ \\
\hline Per capita total OOP in INR & -15.064 & (38.269) & $-10.1 \%$ & -19.356 & $(42.785)$ & $-63.409 * *$ & $(28.108)$ \\
\hline Share of OOP in household monthly expenditure & -0.007 & $(0.006)$ & $-9.0 \%$ & -0.009 & $(0.006)$ & $-0.018 * * *$ & $(0.005)$ \\
\hline Catastrophic medical expenditure & -0.005 & $(0.021)$ & $-3.6 \%$ & -0.012 & $(0.022)$ & $-0.039 * * *$ & $(0.015)$ \\
\hline Household took loan to meet medical expenses & 0.026 & $(0.011)$ & $63.9 \%$ & $0.033^{* *}$ & $(0.015)$ & $0.023 * *$ & $(0.011)$ \\
\hline Per capita expenditure on ST morbidity & 4.524 & $(12.550)$ & $10.0 \%$ & 4.691 & $(13.546)$ & 32.056 & $(47.635)$ \\
\hline Per capita expenditure on LT morbidity & 30.402 & $(43.254)$ & $56.3 \%$ & 53.282 & $(30.398)$ & 112.720 & $(132.115)$ \\
\hline Per capita expenditure on medicines & 24.841 & $(37.905)$ & $51.2 \%$ & 42.075 & $(34.733)$ & 107.087 & $(124.812)$ \\
\hline Per capita expenditure on hospital and doctors & 9.074 & $(9.520)$ & $35.9 \%$ & 11.633 & $(12.384)$ & 65.351 & (44.119) \\
\hline Per capita total OOP from individual modules & 34.926 & $(32.076)$ & $35.2 \%$ & 34.926 & $(32.076)$ & 144.776 & $(140.440)$ \\
\hline
\end{tabular}

Note: Standard errors are in the parenthesis. For matching, standard errors are derived through bootstrap with 50 replication. Fixed effects standard errors are clustered at household level. *** $p<0.01, * * p<0.05, * p<0.1$ 
Table 8: Impact of RSBY conditional on having received medical treatment (patient level) for long term disease

\begin{tabular}{|c|c|c|c|c|c|c|}
\hline \multirow[b]{3}{*}{ Panel A: Rural } & \multicolumn{3}{|c|}{ DID, pooled cross section } & \multicolumn{3}{|c|}{ Single difference } \\
\hline & $A T T$ & $S E(A T T)$ & $\begin{array}{c}\text { ATT as \% of } \\
\text { RSBY patients' } \\
2005 \text { level }\end{array}$ & $A T T$ & $S E(A T T)$ & $\begin{array}{r}\text { ATT as \% of } \\
\text { RSBY patients' } \\
2005 \text { level }\end{array}$ \\
\hline & (1) & (2) & (3) & (4) & (5) & (6) \\
\hline Hospitalized & $0.046^{*}$ & $(0.025)$ & $16.2 \%$ & 0.022 & $(0.015)$ & $7.5 \%$ \\
\hline Treatment by government doctor & 0.042 & $(0.032)$ & $14.0 \%$ & $0.063 * * *$ & $(0.014)$ & $20.8 \%$ \\
\hline Expenditure on medicines & $-124.429 * *$ & $(63.083)$ & $-30.9 \%$ & $-139.859 * * *$ & $(53.770)$ & $-34.7 \%$ \\
\hline Expenditure on hospital* & 20.145 & $(51.455)$ & $15.5 \%$ & $-34.390^{*}$ & $(18.450)$ & $-26.5 \%$ \\
\hline Total out-of-pocket & -14.532 & $(131.837)$ & $-1.9 \%$ & $-145.230 * *$ & $(59.791)$ & $-18.6 \%$ \\
\hline Days lost & 3.423 & $(6.321)$ & $6.3 \%$ & $4.851^{*}$ & $(2.531)$ & $8.9 \%$ \\
\hline Days in hospital & -0.187 & $(0.775)$ & $-4.2 \%$ & -0.253 & $(0.263)$ & $-5.7 \%$ \\
\hline \multicolumn{7}{|l|}{ Panel B: Urban } \\
\hline Hospitalized & -0.014 & $(0.036)$ & $-4.1 \%$ & 0.030 & $(0.019)$ & $9.1 \%$ \\
\hline Treatment by government doctor & -0.028 & $(0.039)$ & $-7.4 \%$ & $0.059 * *$ & $(0.024)$ & $15.5 \%$ \\
\hline Expenditure on medicines & 259.143 & (274.247) & $70.4 \%$ & 182.109 & $(225.643)$ & $49.5 \%$ \\
\hline Expenditure on hospital* & -35.530 & $(51.214)$ & $-22.5 \%$ & 14.636 & $(24.871)$ & $9.3 \%$ \\
\hline Total out-of-pocket & 256.293 & $(270.490)$ & $32.9 \%$ & 250.755 & (195.640) & $32.1 \%$ \\
\hline Days lost & 1.652 & (7.209) & $3.7 \%$ & 4.786 & (3.649) & $10.7 \%$ \\
\hline Days in hospital & 2.098 & $(3.458)$ & $34.2 \%$ & $0.862 * *$ & $(0.431)$ & $14.1 \%$ \\
\hline
\end{tabular}




\section{Appendix}

Table-A1: Post matching difference in 2005 correlates

\begin{tabular}{|c|c|c|c|c|c|c|c|c|}
\hline & (1) & (2) & (3) & (4) & $(5)$ & $(6)$ & (7) & (8) \\
\hline & \multicolumn{4}{|c|}{ Rural } & \multicolumn{4}{|c|}{ Urban } \\
\hline & Treated & Control & \%bias & $\begin{array}{l}p \text {-value } \\
(1)=(2)\end{array}$ & Treated & Control & \%bias & $\begin{array}{l}p \text {-value } \\
(5)=(6)\end{array}$ \\
\hline Other Backward Castes+ & 0.335 & 0.320 & 3.100 & 0.239 & 0.331 & 0.287 & 9.600 & 0.041 \\
\hline Scheduled Castes+ & 0.279 & 0.271 & 1.700 & 0.527 & 0.158 & 0.156 & 0.600 & 0.901 \\
\hline Scheduled Tribes+ & 0.112 & 0.118 & -1.700 & 0.522 & 0.032 & 0.039 & -4.200 & 0.387 \\
\hline Muslim+ & 0.089 & 0.096 & -2.500 & 0.341 & 0.154 & 0.161 & -1.800 & 0.695 \\
\hline Household Size & 6.011 & 6.177 & -5.400 & 0.032 & 5.544 & 5.536 & 0.300 & 0.944 \\
\hline Household Size Square & 44.348 & 46.714 & -4.200 & 0.076 & 36.864 & 36.783 & 0.200 & 0.964 \\
\hline$\%$ of age $0-14$ in $\mathrm{HH}$ & 0.325 & 0.328 & -1.300 & 0.615 & 0.272 & 0.265 & 3.400 & 0.459 \\
\hline$\%$ of age 61 and above in $\mathrm{HH}$ & 0.072 & 0.069 & 2.100 & 0.414 & 0.059 & 0.063 & -2.600 & 0.558 \\
\hline$\%$ of age $15-49$ female in $\mathrm{HH}$ & 0.246 & 0.244 & 1.300 & 0.615 & 0.278 & 0.277 & 0.600 & 0.900 \\
\hline log per capita consumption & 6.829 & 6.835 & -0.900 & 0.738 & 7.296 & 7.340 & -6.800 & 0.139 \\
\hline log of per capita income & 8.888 & 8.875 & 0.900 & 0.744 & 9.672 & 9.678 & -0.500 & 0.923 \\
\hline No ration card+ & 0.123 & 0.124 & -0.200 & 0.926 & 0.146 & 0.152 & -1.800 & 0.700 \\
\hline BPL card+ & 0.384 & 0.353 & 6.500 & 0.017 & 0.260 & 0.238 & 5.300 & 0.277 \\
\hline Poor+ & 0.319 & 0.310 & 2.000 & 0.467 & 0.274 & 0.244 & 7.100 & 0.142 \\
\hline Head age & 47.947 & 47.772 & 1.300 & 0.617 & 47.864 & 48.367 & -3.900 & 0.395 \\
\hline Head is female+ & 0.092 & 0.086 & 2.000 & 0.461 & 0.111 & 0.115 & -1.400 & 0.772 \\
\hline Head's education & 3.975 & 3.991 & -0.400 & 0.885 & 6.943 & 7.086 & -3.000 & 0.518 \\
\hline Head's work type-casual+ & 0.553 & 0.542 & 2.200 & 0.419 & 0.363 & 0.331 & 6.900 & 0.136 \\
\hline Head's work-type-government+ & 0.045 & 0.045 & 0.200 & 0.921 & 0.190 & 0.196 & -1.500 & 0.757 \\
\hline Per capita inpatient expenditure & 58.532 & 67.427 & -2.700 & 0.432 & 77.474 & 76.110 & 0.300 & 0.947 \\
\hline Per capita outpatient expenditure & 93.197 & 82.507 & 3.300 & 0.196 & 69.361 & 73.670 & -1.600 & 0.661 \\
\hline$\%$ of members reported- fever & 0.140 & 0.131 & 4.900 & 0.070 & 0.106 & 0.105 & 0.800 & 0.860 \\
\hline$\%$ of members reported- cough & 0.111 & 0.103 & 4.600 & 0.087 & 0.081 & 0.079 & 1.600 & 0.726 \\
\hline $\begin{array}{l}\text { \% of members reported- diarrhea } \\
\% \text { of members reported- short term }\end{array}$ & 0.042 & 0.038 & 3.300 & 0.229 & 0.021 & 0.020 & 1.000 & 0.821 \\
\hline $\begin{array}{l}\text { (ST) problems } \\
\% \text { of members reported- received }\end{array}$ & 0.157 & 0.149 & 4.100 & 0.124 & 0.120 & 0.120 & 0.100 & 0.976 \\
\hline $\begin{array}{l}\text { treatment for ST problems } \\
\% \text { of members reported-government }\end{array}$ & 0.147 & 0.137 & 5.100 & 0.055 & 0.114 & 0.113 & 0.300 & 0.957 \\
\hline $\begin{array}{l}\text { doctor for } \mathrm{ST} \\
\% \text { of members reported-private }\end{array}$ & 0.032 & 0.028 & 3.800 & 0.152 & 0.025 & 0.026 & -0.300 & 0.948 \\
\hline $\begin{array}{l}\text { doctor for ST problem } \\
\% \text { of members reported- long term }\end{array}$ & 0.103 & 0.099 & 2.600 & 0.326 & 0.076 & 0.074 & 1.000 & 0.831 \\
\hline (LT) problems & 0.067 & 0.061 & 4.000 & 0.137 & 0.074 & 0.076 & -1.200 & 0.797 \\
\hline$\%$ of members reported-cataract & 0.007 & 0.006 & 1.900 & 0.480 & 0.003 & 0.003 & -0.600 & 0.890 \\
\hline $\begin{array}{l}\% \text { of members reported- tuberculosis } \\
\% \text { of members reported- blood }\end{array}$ & 0.004 & 0.003 & 0.800 & 0.761 & 0.003 & 0.002 & 2.900 & 0.541 \\
\hline $\begin{array}{l}\text { pressure } \\
\% \text { of members reported- heart }\end{array}$ & 0.013 & 0.014 & -0.900 & 0.769 & 0.022 & 0.026 & -5.500 & 0.226 \\
\hline disease & 0.004 & 0.005 & -3.200 & 0.299 & 0.007 & 0.008 & -2.100 & 0.627 \\
\hline
\end{tabular}




\begin{tabular}{|c|c|c|c|c|c|c|c|c|}
\hline$\%$ of members reported- diabetes & 0.007 & 0.008 & -2.500 & 0.427 & 0.014 & 0.014 & -0.500 & 0.919 \\
\hline$\%$ of members reported- leprosy & 0.001 & 0.000 & 3.900 & 0.126 & 0.001 & 0.001 & 0.000 & 0.995 \\
\hline$\%$ of members reported- cancer & 0.000 & 0.000 & -0.300 & 0.867 & 0.001 & 0.001 & -0.700 & 0.836 \\
\hline$\%$ of members reported- asthma & 0.008 & 0.008 & 0.300 & 0.922 & 0.005 & 0.005 & 0.100 & 0.983 \\
\hline$\%$ of members reported-polio & 0.001 & 0.001 & 0.600 & 0.821 & 0.001 & 0.000 & 2.100 & 0.602 \\
\hline Per capita hospital days & 0.248 & 0.250 & -0.100 & 0.971 & 0.551 & 0.533 & 0.400 & 0.946 \\
\hline Per capita days lost in illness & 4.251 & 3.944 & 2.200 & 0.395 & 3.699 & 3.344 & 2.500 & 0.554 \\
\hline HH has piped water access+ & 0.206 & 0.207 & -0.400 & 0.889 & 0.680 & 0.670 & 2.200 & 0.625 \\
\hline HH has hand pump water access+ & 0.409 & 0.406 & 0.600 & 0.823 & 0.136 & 0.141 & -1.300 & 0.759 \\
\hline $\mathrm{HH}$ has no access to toilet+ & 0.743 & 0.729 & 3.200 & 0.220 & 0.297 & 0.274 & 5.100 & 0.279 \\
\hline HH has no electricity+ & 0.404 & 0.398 & 1.100 & 0.675 & 0.071 & 0.067 & 1.700 & 0.725 \\
\hline House building in poor conditions+ & 0.194 & 0.185 & 2.200 & 0.410 & 0.166 & 0.152 & 3.900 & 0.401 \\
\hline $\mathrm{HH}$ have health insurance+ & 0.017 & 0.015 & 1.400 & 0.589 & 0.037 & 0.047 & -5.000 & 0.279 \\
\hline HH use radio+ & 0.131 & 0.142 & -3.300 & 0.217 & 0.111 & 0.103 & 2.600 & 0.566 \\
\hline HH use paper+ & 0.118 & 0.118 & -0.200 & 0.936 & 0.427 & 0.445 & -3.700 & 0.423 \\
\hline HH use Television+ & 0.205 & 0.210 & -1.000 & 0.689 & 0.572 & 0.596 & -4.800 & 0.299 \\
\hline HH know some doctor+ & 0.308 & 0.295 & 2.700 & 0.311 & 0.359 & 0.368 & -1.900 & 0.685 \\
\hline HH know some teacher+ & 0.372 & 0.390 & -3.600 & 0.175 & 0.440 & 0.443 & -0.500 & 0.913 \\
\hline HH know some government servant+ & 0.257 & 0.264 & -1.600 & 0.533 & 0.412 & 0.434 & -4.400 & 0.332 \\
\hline HH suffered death in last year+ & 0.052 & 0.047 & 2.200 & 0.416 & 0.021 & 0.023 & -1.000 & 0.810 \\
\hline $\begin{array}{l}\text { Confidence in hospital/doctors } \\
\text { Great deal of confidence in state }\end{array}$ & 0.633 & 0.621 & 2.500 & 0.346 & 0.682 & 0.670 & 2.600 & 0.572 \\
\hline government & 0.277 & 0.271 & 1.500 & 0.584 & 0.264 & 0.263 & 0.200 & 0.968 \\
\hline Large village- 5000 population+ & 0.231 & 0.229 & 0.400 & 0.877 & & & & \\
\hline Distance to town in $\mathrm{km}$ & 14.352 & 14.076 & 2.500 & 0.352 & & & & \\
\hline Distant to district $\mathrm{HQ}$ in $\mathrm{km}$ & 41.891 & 43.085 & -4.500 & 0.084 & & & & \\
\hline No access to surfaced roadt & 0.911 & 0.907 & 1.400 & 0.613 & & & & \\
\hline No bus stop in village+ & 0.533 & 0.526 & 1.400 & 0.595 & & & & \\
\hline Number of anganwadis in village & 3.221 & 3.170 & 1.100 & 0.722 & & & & \\
\hline Health sub center in village+ & 0.382 & 0.389 & -1.400 & 0.603 & & & & \\
\hline Primary health center in village+ & 0.176 & 0.178 & -0.500 & 0.859 & & & & \\
\hline Village have trained private doctor+ & 0.234 & 0.220 & 3.500 & 0.180 & & & & \\
\hline
\end{tabular}
Note: + implies indicator variable. 